\title{
HORIZONTES DA TRADUÇÃO NA AMÉRICA LATINA
}

\section{HORIZONS OF TRANSLATION IN LATIN AMERICA}

\section{Dennys Silva-Reis* Liliam Ramos da Silva*}

A palavra borizonte em língua portuguesa pode ser compreendida, dentre tantos outros sentidos, como ponto de vista, domínio circunscrito de uma área, limiar de alguma coisa ou dimensão futura de algo. Logo, as acepções de horizonte para cada indivíduo ou coletivo serão múltiplas, o que possibilita o uso de borizontes no plural. Discursar sobre os borizontes da tradução é considerar a diversidade de campos, enfoques, abordagens e sujeitos envolvidos no ato da tradução enquanto produto e processo.

Antoine Berman, em seu método de crítica de tradução Pour une critique des traductions: Jobn Donne, talvez tenha sido o primeiro teórico dos Estudos de Tradução a falar sobre horizonte, em particular sobre o borizonte do tradutor. Segundo Berman (1995, p.79) "pode-se definir em primeira aproximação o horizonte como o conjunto dos parâmetros linguageiros, literários, culturais e históricos que 'determinam' o sentir, o agir e o pensar de um tradutor ${ }^{1 \prime \prime}$, o que significa reconhecer que um tradutor está inserido em um tempo/espaço, um contexto que não condiciona estritamente seu fazer, mas que de alguma forma o afeta. O estudioso ainda diz mais:

A noção de horizonte tem uma dupla natureza. De uma parte, designando este-a-partir-de-que o agir do tradutor tem um sentido e pode se desdobrar, aponta o espaço aberto deste agir. Mas, de outra parte, designa o que éfechado, o que encarcera o tradutor em um círculo de possibilidades limitadas. (BERMAN, 1995, p. 80-81, itálicos do autor)

Ou seja, é preciso considerar que vários aspectos estão envolvidos no ato de traduzir (o espaço aberto) e que um tradutor pode ou não dar maior ênfase a um deles. Entretanto, todos os elementos que envolvem o ato de traduzir são oriundos do texto a ser traduzido (o círculo fechado). Dessa forma, o que Antoine Berman parece afirmar é que os horizontes do tradutor e os horizontes da tradução,

\footnotetext{
*Universidade de Brasília (UnB), Brasília (DF), Programa de Pós-Graduação em Literatura - POSLIT. Brasil.reisdennys@gmail.com

* Universidade Federal do Rio Grande do Sul (UFRGS), Porto Alegre (RS), Brasil. liliamramos@gmail.com 1. Todas as traduções de citações, quando não creditadas ao tradutor, são dos autores do texto.
} 
mais especificamente, do autor do texto a ser traduzido, precisam se fundir, ser compartilhados.

Um texto em tradução impregna em si diversos horizontes, dentre eles: o horizonte de experiência, o horizonte de expectativa, o horizonte de mundo e o horizonte de ação - conceitos propostos por Paul Ricoeur (1991, 2010) e Hans Robert Jauss (2004, 2005). Grosso modo, borizonte de experiência dizse da presentificação do passado por uma elaboração racional (por vezes, memorial); borizonte de expectativa seria um sistema de referências objetivamente formulado no ato da leitura; borizonte de mundo é a referência ou denotação de um discurso; e entende-se borizonte de ação como os traços constitutivos de um discurso marcadamente temporal e intersubjuntivo. É a partir da fusão desses horizontes que no ato de traduzir há o que Antoine Berman nomeia de- ou recontextualização. De fato, Berman considera que tais horizontes são conceitos fundamentais da hermenêutica que contribuem para: 1) a análise da dimensão tradutiva das traduções de forma não estruturalista e 2) observar o tradutor além de mero dispositivo de transmissão, um relais nas palavras do autor.

Abordar os horizontes de tradução é igualmente discorrer sobre os aspectos poéticos, éticos, históricos e políticos da tradução. Todavia, para se pensar os horizontes da tradução na América Latina, convém refletir: o que, de fato, se caracteriza como América Latina? Que elementos sociais, políticos e culturais a identificam como espaço compartilhado de saberes? Como esses conceitos se relacionam com a tradução e com o tradutor? Qual a relevância das literaturas escritas em países latino-americanos traduzidas no Brasil e no exterior? E de que forma esses textos se inserem no sistema literário brasileiro e estrangeiro?

Historicamente, a ideia de América Latina surgiu como convenção imperialista francesa ligada ao princípio de panlatinismo, ou seja, uma "aproximação cultural entre a França e as nascentes repúblicas de língua espanhola, a partir de uma união 'latina' intercontinental, mas que obviamente teria a França como liderança" (FARRET, PINTO, 2011, p. 35), entretanto, o conceito ou nome substantivado surge em 1853 nos versos do poema "Las dos Américas" de José Maria Torres Caicedo (1830-1889) (Apud ADAO, 1995, p. 182):

Más aislados se encuentran, desunidos,

Esos pueblos nacidos para aliarse:

La unión es su deber, su ley amarse:

Igual origen tienen y misión;

La raza de la América latina,

$\mathrm{Al}$ frente tiene la sajona raza, 
Enemiga mortal que ya amenaza

Su libertad destruir y su pendón.

Se já no século XIX, tanto o conceito quanto a ideia eram comuns entre os intelectuais, será somente no século XX que o Brasil será incluído no conceito de Latin America. Segundo João Feres Jr. (2004), esse conceito, constructo norteamericano cristalizado durante todo o século XX que ainda assombra o senso comum atualmente, é composto por três assimetrias semânticas: (1) a cultural, (2) a temporal e (3) a racial. (1) Enquanto a América detém os bons costumes, hábitos e instituições, a América Latina seria sua negação. (2) Ao passo que a América se encontra progressista, moderna e desenvolvida, a América Latina seria seu oposto. (3) Ao mesmo tempo que a América Latina é um espaço mestiço e não-branco, a América seria branca e anglo-saxônica. Por outro lado, do ponto de vista das comunidades latino-americanas, cabe destacar que o termo "Latina", ao caracterizar o subcontinente a partir de uma proximidade de origem etimológica privilegiando os idiomas oficiais impostos pelo colonizador, exclui já em seu nome a participação dos indígenas e afrodescendentes como componentes identitários desse espaço que, desde a chegada dos europeus, depara-se com movimentos de inserção e exclusão de culturas conforme desenvolvimento dos processos de formação de nacionalidades. Intelectuais como o argentino García Canclini (2013) não acreditam que haja uma identidade latino-americana e, sim, um espaço sociocultural compartilhado, um lugar dinâmico e em transformação, com histórias comuns de conquista e colonização, porém com realidades tão diversas que se torna complexa, portanto, a tentativa de classificação do espaço em uma só palavra.

Apesar da consolidação dessas assimetrias semânticas, os esforços teóricos de mudar essa visão negativa sobre a América Latina e o latino-americano foram empreendidos com grande sagacidade com os escritos de José Martí (18531895) em seu manifesto Nuestra América (1891) e de José Enrique Rodó (18711917), especialmente nas obras Ariel (1900) e El Mirador de Próspero (1913), que denunciavam a nortemania e a doutrina do utilitarismo. Martí instigava a uma segunda independência, naquele momento cultural e econômico, em posição ideológica contrária ao expansionismo estadunidense. Posteriormente, vários escritos foram surgindo a partir do desenvolvimento dos Estados-nações latino-americanos (DIAS, 2009; BETHELL, 2009).

$\mathrm{Na}$ contemporaneidade, ao se referirem à América Latina, teóricos definem o espaço limitando-o à junção do México aos Estados independentes da América 
Central e da América do Sul². Essa seria uma definição geográfico-política dominante, apesar de haver um consenso igualmente reinante em que América Latina estaria relacionada apenas aos países em que se falam línguas derivadas do latim - o que não procede mais. As discussões de qual seria o denominador comum da região atualmente chamada América Latina mais revelam fraturas do que elementos de unidade quanto aos aspectos históricos, políticos e sociais (BEYHAUT, 1994). Entretanto, o historiador uruguaio Gustavo Beyhaut (1994) afirma que um dos grandes aspectos de unidade da América Latina é a dimensão cultural.

Se, por um lado, há na América Latina, como mostra Beyhaut (1994), disparidades do Estado-nação, diferenças de modelos econômicos, diversidade de línguas, marginalização étnica, papel ambíguo das fronteiras; por outro lado, há igualmente nessa região uma integração que se realiza em nível de culturas. Beyhaut (1994) defende que as formas de integração nas artes (em particular, literatura, arquitetura e música) e nas ideias estão intimamente relacionadas aos fatores e às formas sociais que as favorecem como os movimentos demográficos (migração, imigração, exílio, êxodos, etc.) e as trocas entre mentalidades (crenças, opiniões e comportamentos).

O sociólogo mexicano Carlos Aguirre Rojas (2001) propõe que para entender a América Latina atual faz-se necessário partir da realidade estrutural do continente, desde a época dos colonizadores europeus até os dias de hoje. Desde seu início, seu processo civilizatório foi construído não em função de si mesma, mas sempre em função dos diferentes centros hegemônicos, da economia capitalista mundial e do sistema histórico global. A América Latina, portanto, surge como uma civilização periférica e submissa, que desenvolve seus sistemas se apropriando de modelos culturais europeus e, logo, estadunidenses, e cuja economia e sociedade se edificam não para seu próprio desenvolvimento, mas sim direcionado a essas potências e metrópoles:

2. Fazem parte da América Latina os seguintes países: Antígua e Barbuda, Argentina, Bahamas, Barbados, Belize, Bolívia, Brasil, Chile, Colômbia, Costa Rica, Cuba, Dominica, El Salvador, Equador, Granada, Guatemala, Guiana, Haiti, Honduras, Jamaica, México, Nicarágua, Panamá, Paraguai, Peru, República Dominicana, Santa Lúcia, São Cristóvão e Névis, São Vicente e Granadinas, Suriname, Trinidad e Tobago, Uruguai e Venezuela. Porto Rico, com status de Estado Livre Associado aos Estados Unidos, não é um Estado independente. Os Estados Unidos cuidam dos assuntos financeiros e de política exterior, mas, mesmo sendo considerado um estado da federação, Porto Rico não tem representantes no Congresso estadunidense. O mesmo vale para outras possessões: as Ilhas Virgens Americanas (EUA); Guadalupe, Martinica, Saint-Martin e Guiana Francesa (França); Bonaire, Curaçao, Aruba e São Martinho (Países Baixos); Ilhas Cayman, Turks e Caicos, Ilhas Virgens Britânicas, Montserrat e Anguilla (Reino Unido) (DIAS, 2009, p. 55, adaptado pelos autores). 


\begin{abstract}
Porque dado que el nacimiento de nuestra civilización latinoamericana es un proceso simetricamente contemporáneo a la emergencia del capitalismo como sistema histórico, y con ello al nacimiento y afirmación tanto de la primera economía mundial como de la verdadera y estricta historia universal, entonces la suerte que le ha tocado a América Latina en cuanto su integración específica a este capitalismo, a esta economía mundial y a esta historia universal, ha sido la de ser una de las "periferias" o "áreas dominadas" de dichas entidades globales mencionadas. (AGUIRRE ROJAS, 2001, p. 45)
\end{abstract}

Como consequência direta dessa condição periférica e dependente, a América Latina é também uma das regiões mais desiguais do mundo, pois apresenta os maiores e mais brutais contrastes entre suas minorias ricas e maiorias de pessoas pobres e miseráveis. Por outro lado, seu traço cosmopolita permite a abertura e recepção das mais diversas influências e tradições culturais - apresentando-se receptiva e tolerante -, cujas criações e realidades sociais apresentam o vigor, a força e o impulso vitais e pujantes de uma civilização ainda em ascensão. Segundo Aguirre Rojas (2001), a partir de 1968, com o movimento de Revolução Cultural iniciado na França (virada decisiva na definição dos perfis dos estudos históricos dos distintos países do continente), a América Latina se libertará de sua situação de total ou parcial domínio da historiografia positivista e erudita e passará a compor um cenário que permitirá sua abertura ao Outro, tornando-a cada vez mais polifacética entre múltiplas visões e interpretações históricas. Além de dependente e periférica, a América Latina sempre foi "profunda, integral y permanentemente mestiza" (AGUIRRE ROJAS, 2001, p. 48), e o teórico aponta que a grande problemática da importação de teorias eurocêntricas para o espaço latino-americano (e seu parcial funcionamento) se define pela incapacidade dos centros dominantes europeus de compreenderem a diversidade formada no subcontinente e a impossibilidade de explicá-la a partir de teorias construídas para outras realidades. As independências do século XIX conseguiram, em parte, superar o fardo da herança colonial dos povos latino-americanos; no entanto, ainda são perceptíveis as marcas profundas deixadas nas sociedades colonizadas como, por exemplo, o relevante papel da literatura traduzida na formação intelectual dos escritores periféricos bem como na constituição dos sistemas literários nacionais. Escritores e leitores têm acesso à cultura letrada estrangeira via texto traduzido, proporcionando a disputa entre modelos de escrita (tradicionais vs. vanguardistas, entre outros) e oportunizando o debate sobre critérios de integração ou exclusão de autores e obras no sistema.

O conceito de periferia aqui compreendido segue duas percepções: 1) econômica: ex-colônias que ainda mantêm relação de dependência financeira com países desenvolvidos e 2) cultural: em concordância com a interpretação da crítica literária argentina Beatriz Sarlo em Modernidade periférica - Buenos Aires 1920 e 1930 
(2010). Na perspectiva econômica, o historiador mexicano Jaime Preciado (2008, $\mathrm{s} / \mathrm{p})$ aponta que

\begin{abstract}
O uso dos termos centro e periferia, na análise dos sistemas-mundo, não se refere, em primeira instância, a zonas geográficas, regiões ou Estados, mas a processos complexos. Essas zonas se convertem em centrais, porque dominam os processos de exploração e concentração de mais valia, e, da mesma forma, as regiões periféricas são definidas por sua condição de exploradas pelo centro e subordinadas a seus processos centralizadores e concentradores de recursos.

Os processos de centro consistem em relações que combinam salários relativamente altos, tecnologia moderna e um tipo de produção diversificada. Os processos da periferia constituem uma combinação de baixos salários, tecnologia mais rudimentar, resultando num tipo de produção simples.
\end{abstract}

$\mathrm{Na}$ reflexão sobre periferia cultural, Sarlo (2010) analisa, nas primeiras décadas do século XX, o surgimento de uma "cultura de mescla" na qual elite e imigrantes tiveram amplo acesso à escolaridade na Argentina, formando um público leitor que possibilitou o desenvolvimento da mídia impressa e a expansão acelerada do mercado editorial. Aponta que cidades como Buenos Aires e Rosario são "cosmopolitas a partir de baixo", ou seja, cosmopolitas não somente por suas elites, mas também pela integração de centenas de milhares de imigrantes europeus (não seria esse também fato comum em diversas regiões do Brasil?). Configuram-se como cenários de metamorfoses que, ao mesmo tempo, desenvolvem elementos culturais próprios mesclados à tradição europeia, cuja originalidade estaria na cópia, na importação de diferentes fontes e origens, resultado tanto da imitação quanto da bricolagem e da reciclagem: "Buenos Aires se compõe de fragmentos copiados de muitas cidades, recompostos em território latino-americano. A cidade traduz de muitas línguas e de muitos textos em conflito, e mostra as distorções do espaço e da realidade social americana" (SARLO, 2010, s/p). Com a democratização da distribuição e do consumo de artigos culturais, a difusão massiva da cultura europeia progressista no contexto rio-platense se dá através de textos traduzidos, intensificando os debates culturais e estéticos sobre questões como língua (quem fala e/ou escreve em castelhano "aceitável") e tradução (quem está autorizado a traduzir e por quais motivos). É nesse contexto que o escritor e tradutor Jorge Luis Borges (1899-1986), ao regressar da adolescência na Europa e verificar o alto grau de progresso e industrialização da capital argentina, apresenta o conceito de orillas (margens, periferias), aplicado em uma cidade que se vê como moderna mas não possui grandes monumentos nem mitos, uma cidade sem passado e sem fantasmas, uma cidade nova sobre um espaço plano sem atrativos, que demarca o limite entre cultura europeia e o espaço geográfico do pampa: 
essas "orillas" são, ao mesmo tempo, os confins da modernidade europeia, a fronteira entre a cidade e a planura do pampa, que a Borges interessava por seu potencial mítico. Ao voltar da Europa, Borges está na melhor posição para captar a marginalidade da Argentina, sintetizada em Buenos Aires. Nunca abandonará de todo essa posição "marginal". Como ninguém, ele fez das "orillas" um tema literário. Converteu a ausência original numa qualidade argentina, como se vê em seus primeiros livros de poemas: "Fervor de Buenos Aires" (1923), "Cuaderno San Martín" (1925) e "Luna de enfrente" (1929). (SARLO, 2010, s/p)

A literatura periférica configura-se, portanto, como produção de textos que afrontam o cânone, rompendo com as normas e os paradigmas estéticos europeus vigentes. Nesse caso, Sarlo teorizou sobre as relações entre a América Latina (Buenos Aires em particular) e a Europa, analisando as produções de três escritores argentinos do início do século XX, momento pós-independências e de construção de identidades nacionais: Ricardo Güiraldes (escritor de temática regionalista ainda centrado no campo e na figura do gaúcho), Roberto Arlt (de origem imigrante, narrativas urbanas, moderno) e Borges (escritor situado nas orillas, entre tradição e modernidade, como afirmado anteriormente). Falar da condição periférica de um país significa situá-lo com relação a um centro hegemônico cuja matriz é, via de regra, a Europa, responsável pelo estabelecimento de padrões culturais e estéticos, traduzidos nas línguas culturais disseminadas como "de cultura", sobretudo o francês, o alemão e o inglês. No entanto, nos dias atuais, em termos de definição de espaço, o conceito de periferia abarca as regiões afastadas dos centros urbanos, habitadas, em grande parte, por pessoas em situação de vulnerabilidade social, aproximando-se da proposta de periferia econômica anteriormente citada por Preciado (2008). Na América Latina, falar de literatura periférica também é apontar os textos produzidos na periferia do sistema, como a literatura de indígenas e afrodescendentes, bem como a escrita de pessoas que vivenciaram e/ou ainda vivenciam situações de miséria e pobreza em comunidades excluídas de projetos de desenvolvimento urbano.

E é nesse campo que a tradução teve e ainda tem um forte papel. No que concerne aos movimentos demográficos, a latino-americanista Birgit Scharlau (2003) em seu texto Traducir América Latina: genealogía de un tópico de investigación apresenta uma forte argumentação de como a tradução foi primordial para a colonização:

El punto de partida es una crítica del colonialismo, tanto en sus formas históricas como en aquellas configuraciones de poder que han perdurado hasta la actualidad. Cuando se habla de 'cultura', se habla, en consecuencia, de relaciones culturales asimétricas. El discurso poscolonial deconstruye la idea de una copresencia armónica (o por lo menos neutra) de distintas culturas. En su lugar, investiga la desigualdad estructurada por el colonialismo. Los teóricos poscoloniales de la traducción están de acuerdo en que históricamente la traducción ha servido de instrumento para la dominación colonial y lo demuestran a partir de diversos ejemplos históricos. No refieren el concepto de traducción exclusivamente a 
la mediación entre dos lenguas, sino a procesos de transferencia cultural, tal como habían sido descritos anteriormente por Talal Asad (1986). En la mayoría de los casos insisten [...] en la bidireccionalidad de este proceso. Desde esta perspectiva, los colonizados no están por completo a merced de las traducciones; más bien la traducción es para ellos un terreno en el que pueden intervenir contra la preponderancia cultural del colonizador mediante extrapolaciones semánticas propias. (2003, p. 105)

Scharlau destaca que a conquista de terras se deu por meio da intermediação linguística acima de tudo, mas também por meio da mediação cultural no contato entre línguas na América Latina³. Convém mencionar que será essa mediação cultural linguística e de ideais via tradução que trará à tona umas das características mais marcantes do indivíduo latino-americano: a descolonização (SOUZA, 2009).

Será o pensamento a respeito da descolonização (pós-colonialismo e decolonialismo ${ }^{4}$ ) que ressignificará a visão sobre tradução na América Latina, que até o século XX ainda tinha pouca amplitude (SCHARLAU, 2003). Georges Bastin, Álvaro Echeverri e Ángela Campo (2004), ao mencionarem a receptividade das teorias (eurocêntricas) da tradução e a história da tradução na América Latina, afirmam que o posicionamento prático e teórico latino-americano é a apropriação. Nas palavras dos autores, "la apropiación es una modalidad creativa de la traducción tendiente a consolidar la identidad de la colectividad a la que pertenece el traductor. Es también un proceder selectivo en el que el traductor escoge sólo lo que resulta útil para sus propósitos" (BASTIN, ECHEVERRI, CAMPO, 2004, p. 72). Ou seja, o sentido de apropriação aqui utilizado não é sinônimo de tornar próprio algo de outrem, mas de adequar ou dar pertinência a algo. Muito diferente da tradição francesa das Belles Infidèles, que embelezava a tradução ao gosto do público francês, a tradução apropriada é um meio sagaz de tornar o instrumento colonizador algo decolonizado.

Bastin, Echeverri e Campo (2004), em seu texto "La traducción en América Latina: Propia y Apropiada", dão vários exemplos de como os atos de tradução foram ressignificados por seus tradutores. Os pesquisadores ainda propõem uma tipologia de tradução apropriada na América Latina como projeto sociocultural, político e educativo:

El primero apunta a la construcción de un hombre nuevo por la sencilla razón de que el descubrimiento de Colón y sus consecuencias impidieron al americano seguir siendo el que era, por la circunstancia del mestizaje racial impuesto al subcontinente. Esta mezcla racial dio

3. Marcos Bagno, em seu artigo Tradução: espelho da mudança? Mafalda responde, analisa mudanças linguísticas ocorridas no português brasileiro que o afastam progressivamente do português europeu, mudanças devidas aos múltiplos contatos linguísticos durante o longo período colonial.

4. Para mais detalhes sobre a diferença entre as duas correntes e os conceitos pós-colonial e decolonial, aqui utilizados, ler o artigo "América Latina e o giro decolonial" de Luciana Ballestrin (2013). 
lugar a un mestizaje más profundo en lo intelectual y afectivo del hombre americano. Los contactos que tuvieron lugar a través de la traducción también apuntaban a ese objetivo de moldear un hombre socioculturalmente nuevo.

El segundo proyecto emancipador iniciado a principios del siglo XVIII, es de corte político, se manifiesta en sublevaciones, rebeliones y guerras y se expresa en pasquines, canciones, arengas, cartas, ensayos filosóficos y textos oficiales. Constituye un discurso anticolonial y antiimperialista tendiente a llevar a cabo el proyecto republicano, a echar nuevas bases para la organización política postcolonial.

El tercer proyecto, también iniciado en el siglo XVIII, tiene como objetivo la formación de generaciones de relevo imbuidas del saber universal pero con espíritu americano. (BASTIN, ECHEVERRI, CAMPO, 2004, p. 72)

Convém mencionar que a visada teórica desses autores está diretamente ligada aos aspectos da tradução escrita. Porém, Beyhaut afirma que

Nos estudos dessas mudanças [as trocas entre mentalidades, crenças, opiniões e comportamentos] a metodologia empregada tende a mudar progressivamente. Houve um tempo em que se pensou serem essas trocas detectadas verificando-se a influência da difusão de livros e, em particular, de autores, deixando-se levar pelo rigor metodológico da chamada História das ideias. É verdade que o catolicismo, o enciclopedismo, o liberalismo, o positivismo, o marxismo e o anarquismo constituem corpos coerentes que podem ser rastreados pela pesquisa em bibliotecas, traduções, publicações periódicas e análises de textos. No entanto, hoje vigora uma atitude mais cética com relação à importância exclusiva dos meios cultos de difusão dessas ideias - porque influenciam diretamente as populações analfabetas ou semianalfabetas. Assim, nos tempos mais recentes verifica-se a crescente importância do rádio, do cinema e da televisão. (BEYHAUT, 1994, p. 195)

Isto é, além das traduções escritas terem sido, de fato, parte importante dos projetos socioculturais, políticos e educativos para a evolução da História das ideias e dos comportamentos na América Latina, de mesmo modo, se percebe, especialmente na contemporaneidade, um forte apelo das traduções intersemióticas e das traduções audiovisuais dentro da vertente tradução apropriada. Os estudos sobre esses dois tipos de tradução se multiplicam na academia cada vez mais, tanto no intuito de decolonizar o tipo de tradução feita ao modo eurocêntrico, como também de propor modos de tradução, especialmente no que concerne à acessibilidade, à melhor apreciação de um produto audiovisual ${ }^{5}$, à formação de tradutores e à proposição de um pensamento teórico nessas especificidades da tradução.

O olhar latino-americano para a tradução enquanto prática e enquanto teoria vem despertando crescente interesse - basta observar o número de cursos, pósgraduações, revistas, livros e notícias sobre esse âmbito na região. Somado a ele, há

5. No presente dossiê, o texto A literatura no rádio e na televisão: traduções intersemióticas na América Latina?, de Dennys Silva-Reis, discute esta questão. 
também o olhar dos especialistas em tradução na América Latina, o que significa pensar que a particularidade da tradução neste local tem se tornado, atualmente, um grande campo de estudos. Scharlau (2004) recorda que por muito tempo o estudo da tradução na região ocupou um espaço marginal em várias áreas do saber entre os latino-americanistas. Nas palavras da autora, "las traducciones y América Latina como el lugar en que se realizan y se inscriben, se perfila solamente a partir de los años ochenta del siglo XX" (SCHARLAU, 2004, p. 21). Isto é, antes até poderiam existir textos que estudassem a tradução na região, mas eram textos que não consideravam a situacionalidade de sua produção e de seu agente de tradução. Felizmente, essa situação vem sendo modificada e hoje já é possível constatar um forte interesse em estudar a tradução dentro de seu contexto latino-americano e em "conciliar las traducciones como objetos de estudio con las situaciones concretas" (SCHARLAU, 2004, p. 24) ${ }^{6}$.

A partir desta possibilidade de estudar a tradução em situações concretas na América Latina, Scharlau (2004) propõe que há ao menos três grandes campos de investigação ao falarmos de estudos de tradução: 1) traduzir entre o âmbito ameríndio e não-ameríndio ${ }^{7}$, 2) traduzir literatura estrangeira ${ }^{8}$, e 3) traduzir textos que refletem sobre as relações coloniais de poder ${ }^{9}$. Ao primeiro campo de investigação o ato de traduzir foi primeiramente trabalho como um discurso sobre o outro no tocante a reconstruir a qualidade da diferença do ameríndio. Neste campo, o ato de traduzir se encontra como um problema estético, ético e mesmo como correção étnica. Além disso, toca pontos crucias da literatura ameríndia como a oralidade, o léxico e distância linguística e cultural. No que tange ao segundo campo de investigação, a tradução entra cena principalmente para pôr em jogo parâmetros estético-literários de identidade da literatura estrangeira e da literatura latino-americana. Está diretamente ligada à constituição das literaturas nacionais e

6. O texto Não me chame de mulata: uma reflexão sobre a tradução de literatura afrodescendente no Brasil no par de línguas espanbol-português, de Liliam Ramos da Silva, parte de uma reivindicação dos movimentos negros em não utilizar o termo mulata, de cunho estereotipante e preconceituoso.

7. É inquietante observar os escassos estudos de tradução relacionados à cultura indígena. $\mathrm{O}$ dossiê conta com apenas um texto relacionado à temática: Tendencias deformantes y paratextos en la traducción al inglés de Huasipungo, de Jorge Icaza, de Pilar Cobo González e Roberto Bein.

8. Texto do dossiê que contempla estudos de tradução através da análise de obra específica: Traducir el extrañamiento y la metapoética: decisiones en la traducción rio-platense de Imágenes (Eikones) de Luciano de Samosata, de Gabriela Baralle e Ivana Chialva.

9. O texto A tradução como política linguística: o caso da Unasul, de Guilherme Queiroz, Marcos Bagno e Julio César Neves Monteiro, reflete sobre essa questão. 
ao procedimento de transculturação na apropriação de modelos estrangeiros ${ }^{10}$. Já o terceiro campo de investigação, Scharlau (2004, p. 28) menciona que

uno de sus rasgos más fuertes lo constituye la conceptualización de la traducción como proceso bidireccional, como movimiento pendular conflictivo entre colonizadores y colonizados (Scharlau, 2003, p.103). El colonizador asimila, traduciendo, a los nativos. Éstos por su parte esquivan, también traduciendo (pero de otro modo), la asimilación e imprimen sus huellas en los textos extranjeros. La traducción no es aquí solamente un instrumento de asimilación, sino que es apropiada por quienes deben ser asimilados o están siéndolo. En este sentido son reinterpretadas también las estrategias interculturales de escritura de ciertos autores mestizos - como por ejemplo el lnca Garcilaso de la Vega (Jakfalvi-Leiva, 1984). Finalmente, los representantes del discurso poscolonial extienden la figura crítica hasta el siglo XX y XXI analizando por ejemplo las adaptaciones de conceptos marxistas en el pensamiento andino (Melgar Bao, 1995-1997) o su imbricación con la cosmología amerindia a través de la traducción - como en el caso del movimiento zapatista en México hoy (Mignolo/Schiwy, 2002).

Isto é, a tradução analisada do ponto de vista político em relação ao binômio colonizador/colonizado ainda é um aspecto ideologicamente muito recorrente nas escolhas de tradutores, editoras e mesmo pensadores latino-americanos da tradução. Esta relação, por vezes, explica por que os latino-americanos são ainda considerados com uma forte cultura de tradução. Por outro lado, também esclarece o porquê do surgimento de outras relações coloniais tradutórias emergentes no Brasil: a tradução feminista, a tradução como diáspora negra, a tradução como voz do subalterno, dentre outros ${ }^{11}$.

É possível acrescentar mais dois campos de investigação que não foram contemplados por Scharlau: a tradução como inclusão e a tradução de textos latinoamericanos (entre os países latino-americanos ${ }^{12}$ e para além desta região). Visto que esta tríade de investigação sugerida por Scharlau (2004) é referente ao corpus de pesquisas sobre tradução entre os anos de 1980 e 2004, percebe-se que nos anos subsequentes outro âmbito de investigação sobre tradução também surgiu com muita força: a tradução como inclusão. Não somente o ser decolonial faz parte destas pesquisas, mas também uma outra gama imensa de seres marginalizados

10. Para verificar como a literatura traduzida pode afetar os sistemas sociais, políticos e culturais na América Latina, sugere-se a leitura de A tradução como potência para a tradição literária, de Karina de Castilhos Lucena e Por uma (po)ética da convivência: Antoine Berman, a América Latina e a tradução em manifesto, de Simone Christina Petry.

11. Conforme os artigos Ina Césaire e os contos crioulos martinicanos: desafios de tradução, de Samanta Vitória Siqueira e Patricia Chittoni Ramos Reuillard e Diáspora negra em contexto de tradução: discutindo a publicação de Mulheres, raça e classe, de Angela Davis, no Brasil, de Luciana de Mesquita Silva.

12. La sintaxis de los enunciados téticos y categóricos en dos traducciones de Corazones solitarios de Ruben Fonseca al español, de Paulo Pinheiro-Correa e Culturas legítimas: la traducción de bistorietas latinoamericanas en Brasil, de Barbara Zocal Silva são exemplos deste tópico no presente dossiê. 
socialmente: as pessoas com deficiência sensorial. A acessibilidade é ponto fulcral neste âmbito de investigações ${ }^{13}$ da tradução inclusiva, tanto do ponto de vista teórico, quanto do ponto de vista prático em que esses estudos estão dando uma contribuição significativa para a sociedade, além de oferecer melhor qualidade de vida para pessoas historicamente esquecidas e marginalizadas no rol dos artefatos e serviços culturais das nações latino-americanas.

Com relação à tradução de textos latino-americanos, é possível notar que um interesse constitutivo das relações entre os países desta região vem sendo desenvolvido cada vez mais tanto pela troca de bens culturais (o audiovisual, em particular) quanto pela busca de uma proximidade de desenvolvimento econômico - exemplo disso é a Comissão Econômica para a América Latina e o Caribe (CEPAL). Para além das relações dos países constituintes da América Latina, o chamado boom da literatura latino-americana a partir da década de 1960 trouxe um interesse muito grande de países distantes da região, o que proliferou em traduções de diversos autores e nas mais variadas línguas. Consequentemente, surgiram institutos e pesquisadores interessados na América Latina e nos textos aqui produzidos, inclusive aos que se dedicam aos Estudos de Tradução como Georges Bastin (Canadá), Patrícia Wilson (Bélgica), Beatriz Scharlau (Alemanha), Gian Luigi De Rosa (Itália), dentre tantos outros.

Em relação aos textos de língua espanhola no Brasil, o tradutor Sergio Bandeira Karam, em sua dissertação de mestrado A tradução de literatura bispano-americana no Brasil: um capítulo da bistória da literatura brasileira (2016), procurou identificar a justificativa ou o propósito editorial que norteou a tradução e a publicação de autores hispanoamericanos no Brasil entre as décadas de 1960 e 1990 para compreender o que significou a circulação dessas obras no sistema literário brasileiro, de que modo elas se integraram (ou não) ao sistema. Como a maioria das traduções foram publicadas em séries ou coleções, sua hipótese é a de que a criação de tais coleções se deveu a razões de fundo eminentemente político-ideológico nas quais as editoras do centro econômico do país (leia-se Rio de Janeiro e São Paulo) objetivavam contribuir com a "unidade latino-americana", em uma tentativa de aproximar os povos da América Latina por meio da literatura, além de tentar responder à questão de por que o

13. O dossiê 2/2017 dedicado à tradução audiovisual acessível da revista Trabalhos em Linguística Aplicada é um forte exemplo deste tipo de investigação acadêmica. E no presente número há três artigos sobre línguas de sinais representativos de três vieses de pesquisas diferentes: Um estudo sobre a formação de tradutores e intérpretes em Língua de Sinais, de Juliana Guimarães Faria e Anabel Galán-Mañas; Competência em tradução e línguas de sinais: a modalidade gestual-visual e suas implicações para uma possível competência tradutória intermodal, de Carlos Henrique Rodrigues e A desambiguação de palavras bomônimas em sentenças por aplicativos de Tradução Automática Português Brasileiro-Libras, de Ygor Corrêa, Rafael Pedruzzi Gomes e Carina Rebello Cruz. 
Brasil estaria de costas para os vizinhos hispânicos. Para tanto, analisou diversos paratextos (prólogos, posfácios, textos de orelhas e contracapas) que confirmam o intuito de divulgar a literatura escrita na América hispânica com recorte nos gêneros ficção e ensaio. É necessário pontuar que nos anos 1960 ocorre o boom da literatura hispano-americana, fato que projetou no mercado editorial mundial escritores que ainda hoje, em sua maioria, pertencem ao cânone hispânico. Interessante destacar que, entre as décadas de 1960 e 1980, a maioria das editoras que publicaram as traduções estavam identificadas, ao menos nominalmente, com um ideário de esquerda, o que fazia aproximar o Brasil principalmente do Chile e da Argentina por conta dos contextos de ditaduras. Já no século XXI percebe-se um alargamento dos critérios de edição e, em épocas de "pós-tudo" (KARAM, 2016, p.10), as editoras apresentam tanto obras de autores menos afamados como autores já reconhecidos nos âmbitos latino-americano e mundial.

Retomando a Teoria dos Polissitemas de Even-Zohar (1990), que corrobora o que já se afirmou anteriormente por Scharlau (2001) - a importância da literatura traduzida para os países periféricos -, Karam analisa a obra O livro no Brasil, de Lawrence Hallewell (2012), que apresenta um estudo com dados provenientes do Serviço de Estatística da Educação e Cultura. Karam questiona a confiabilidade dos dados; no entanto, trabalhando com o que se tem registrado, com esses dados é possível verificar que, entre os anos de 1956 a 1961, foram publicadas 3.044 traduções, das quais 1.298 eram do inglês (42\%), 851 do francês (28\%) e 98 do espanhol (3\%), seguido pelo russo com 70 traduções (2\%). Em Porto Alegre, Karam analisou dados da L\&PM Pocket, um selo da L\&PM Editores, e identificou que, dos 100 primeiros títulos publicados, 58 eram traduções; dessas, 26 eram do inglês (45\%), 15 do francês (26\%) e apenas 9 do espanhol, sendo 7 hispano-americanos (15\%), provavelmente pela proximidade da cidade com os países platinos. Nota-se, pelos dados apresentados, que a literatura hispânica teve pouca circulação no Brasili no entanto, um dado a ser levado em conta é a relativa facilidade que o brasileiro letrado tem na leitura em espanhol, o que poderia ter mascarado os dados sobre a divulgação das traduções das obras no país.

As editoras das universidades brasileiras têm um papel importante na circulação de textos dos Estudos Culturais traduzidos no Brasil. A consolidação da área proporcionou o acesso da academia às produções originalmente escritas por teóricos de países latino-americanos de obras anglófonas, francófonas e hispanófonas (embora muitos já estabelecidos em grandes metrópoles). A Editora UFMG (Universidade Federal de Minas Gerais) foi grande entusiasta na divulgação 
de obras como Da Diáspora - Identidades e mediações culturais ${ }^{14}$, do jamaicano Stuart Hall; O condor voa - literatura e cultura latino-americanas ${ }^{15}$, do peruano Antonio Cornejo Polar; Histórias locais, projetos globais: colonialidade, saberes subalternos e pensamento da margem ${ }^{16}$ do argentino Walter Mignolo e Aqui América Latina - uma especulação $0^{17}$ e $\mathrm{O}$ corpo do delito ${ }^{18}$, da também argentina Josefina Ludmer, além de responsabilizar-se pelas traduções dos indianos Gayatri Spivak (Pode o subalterno falar?) ${ }^{19}$ e Homi Bhabha (O local da cultura $)^{20}$. Dos argentinos José Luis Romero e Néstor García Canclini se publicaram, respectivamente, América Latina, as cidades e as ideias ${ }^{21}$, e Consumidores e cidadãos: conflitos multiculturais da globalização ${ }^{22}$ e do peruano José Carlos Mariátegui, Por um socialismo indo-americano ${ }^{23}$, com tradução pela Editora da UFRJ (Universidade Federal do Rio de Janeiro). A EDUFBA (Universidade Federal da Bahia) ocupou-se da tradução de Pele negra, máscaras brancas ${ }^{24}$, do martinicano Frantz Fanon. As traduções e a circulação de textos de importância mundial salientam o comprometimento das universidades na divulgação do pensamento intelectual contemporâneo.

Salienta-se ainda, no que tange a traduzir textos latino-americanos, um crescente número de editoras e pesquisadores que cada vez mais produzem traduções e textos sobre traduções feitas em países distantes da América Latina. Tais textos revelam sua inserção nos sistemas literários, bem como escolhas tradutórias, projetos editoriais e representações culturais contidas neles ${ }^{25}$. Nota-se, nos Estudos de Tradução do Brasil, um interesse nesse campo de investigação, em particular, no que tange às antologias e projetos editoriais. Exemplo disso é a obra $\mathrm{O}$ Brasil traduzido: palavra estrangeira de Cláudia Borges de Faveri (2015) que traz à tona as implicações de obras brasileiras publicadas na Itália, na França, nos Estados Unidos, na Espanha e na Alemanha. Convém igualmente observar que pesquisadores estrangeiros vêm somando esforços tanto para teorizarem sobre o que é traduzir textos latino-americanos - o caso de Jeremy Munday (2009) em sua obra Style and Ideology in Translation: Latin America writing

14. Tradução de Adriane La Guardia Resende, Ana Carolina Escosteguy, Cláudia Álvares e Francisco Rüdiger (2006).

15. Tradução de Ilka Valle de Carvalho (2000).

16. Tradução de Solange Ribeiro de Oliveira (2003).

17. Tradução de Romulo Monte Alto (2013).

18. Tradução de Maria Antonieta Pereira (1999).

19. Tradução de Sandra Regina Goulart Almeida, Marcos Pereira Feitosa e André Pereira Feitosa.

20. Tradução de Eliana Lourenço de Lima Reis, Gláucia Renate Gonçalves e Myriam Ávila.

21. Tradução de Bella Josef (2004).

22. Tradução de Maurício Santana Dias (2010).

23. Tradução de Luiz Sérgio Henriques (2005)

24. Tradução de Renato da Silveira (2008).

25. O presente dossiê traz essa discussão em Sincretismo religioso como estratégia de sobrevivência transnacional e translacional: divindades africanas e santos católicos em tradução, de Tito Lívio Cruz Romão. 
in English - quanto divulgarem teóricos e pensadores latino-americanos da tradução este é o caso da obra Voice-overs: Translation and Latin: Translation and Latin American Literature de Daniel Balderston e Marcy Schwarts (2002).

Portanto, discutir Horizontes da Tradução na América Latina é novamente repensar o que vem a ser as identidades latino-americanas e que culturas são estas que se nomeiam sob o adjetivo latino-americana. Sob o viés da decolonialidade do poder, do saber e do ser, pode-se dizer que há na América Latina um contínuo pensar da tradução, uma progressiva retradução de valores, experiências e produções que são sempre retextualizados nos Estudos de Tradução e nas práticas de tradução. É neste sentido que se agradece à revista Trabalhos em Linguística Aplicada, em nome da pesquisadora Viviane Veras, pelo espaço aberto a esta discussão.

Para terminar, vale rememorar duas passagens:

A primeira passagem
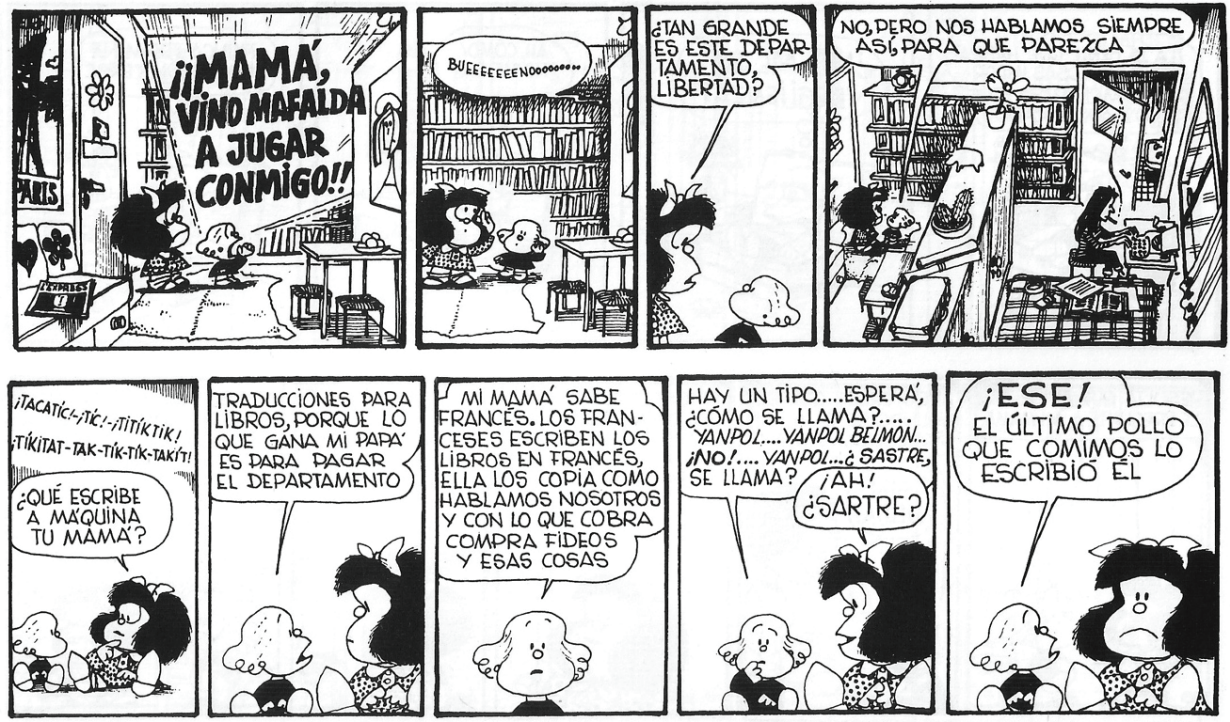

QUINO, Toda Mafalda, 2006, p. 383.

A segunda passagem

- Por qué tú no escribes? - le pregunté de pronto.

- Por qué no te preguntas mejor por qué no traduzco?

-No. Creo que podrías escribir. Si quisieras ...

Guillermo Cabrera Infante, Tres tristes tigres, 1967, p. 236. 
Traduzir e estudar tradução amplia os horizontes do tradutor e do pesquisador latino-americano, mas só se sabe isso escrevendo. Logo, os artigos deste número são uma partilha dos pesquisadores latino-americanos em tradução e sobre a tradução na América Latina, e desse modo, estende-se a todos o convite à leitura do presente dossiê.

\section{REFERÊNCIAS BIBLIOGRÁFICAS}

AGUIRRE ROJAS, C.A. (2001). América Latina: Historia y presente. Morelia: Editorial Jitanjáfora.

ARDAO, A. (1995). La idea de la Magna Colombia en Miranda y Hostos. In: ZEA, Leopoldo (Comp.). Fuentes de la cultura latinoamericana. Tomo I. México: Fondo de Cultura Económica.

BALLESTRIN, L. (2013). América Latina e o giro decolonial. Revista Brasileira de Ciência Política. n.11, p.89-117.

BASTIN, G.; ECHEVERRI, A.; CAMPO, A. (2004). La traducción en América Latina: Propria y Apropriada. Estudios de Investigaciones Literarias y Culturales. Venezuela, $\mathrm{n}^{\circ} 24$, p. 69-94.

BERMAN, A. (1995). Pour une critique des traductions: John Donne. Paris: Gallimard.

BETHELL, Leslie. (2009). O Brasil e a ideia de "América Latina" em perspectiva histórica. Estudos Históricos, Rio de Janeiro, v. 22, n. 44, p. 289-321.

BEYHAUT, G. (1994). Dimensão cultural da integração na América Latina. IEAUSP, Revista de Estudos Avançados, n. 8, p. 183-198.

DIAS, W. S. (2009). A ideia de América Latina nos livros didáticos de geografia. Dissertação de mestrado em Geografia Humana. Faculdade de Filosofia, Letras e Ciências Humanas. São Paulo: Universidade de São Paulo.

EVEN-ZOHAR, I. (1990 [1978]). The Position of Translated Literature within the Literary Polysystem. Polysystem Studies [= Poetics Today 11:1], pp. 45-51.

FARRET, R. L.; PINTO, S. R. (2011). América latina: da construção do nome à consolidação da ideia. Topoi, v. 12 , n. 23 , p. 30-42. 
GARCÍA CANCLINI, N. (2013). Los nombres de América. Documentário. Explora Ciencias Sociales. Buenos Aires: Canal Encuentro. Ministerio de Educación de la República Argentina. Disponível em < https://www.youtube.com/watch?v=o0RRWJIHUcg > Acessado em 08.mar.2018.

HALLEWELL, L. (2012). O livro no Brasil: sua história. Tradução de Maria da Penha Villalobos, Lólio Lourenço de Oliveira e Geraldo Gerson de Souza. São Paulo: Editora da USP.

INFANTE, G. C. (1967). Tres tristes tigres. Venezuela: Biblioteca Ayacucho.

JASS, H.R. (2004). Pour une berménentique littéraire. Paris: Gallimard.

JASS, H.R. (2005). Pour une esthétique de la réception. Paris: Gallimard.

KARAM, S.B. (2016). A tradução de literatura bispano-americana no Brasil: um capítulo da história da literatura brasileira. Dissertação de Mestrado. Porto Alegre: Programa de PósGraduação em Letras/Universidade Federal do Rio Grande do Sul.

MARTÍ, J. (1983). Nossa América - Antologia. Tradução de Maria Angélica de Almeida Trajber. São Paulo: Hucitec, p. 194-201.

QUINO. (1991). Toda Mafalda. Argentina: Ediciones de la Flor.

RICOEUR, P. (1991). Do texto à acção - ensaios de hermenêutica II. Tradução de Alcino Cartaxo e Maria José Sarabando. Lisboa: Rés Editora.

RICOEUR, P. (2010). Tempo e Narrativa 3: O tempo narrado. Tradução de Cláudia Berliner. São Paulo: Martins Fontes.

RODÓ, J. H. (1956). Obras Completas. Compilación y Prólogo por Alberto J. Vaccaro. Buenos Aires: Ed. Antonio Zamora.

SARLO, B. (2007). La máquina cultural. Buenos Aires: Seix Barral.

SARLO, B. (2010). Modernidade Periférica. Buenos Aires 1920 e 1930. Tradução de Júlio Pimentel Pinto. São Paulo: Cosac Naify.

SARLO, B. (2013). Crítica Beatriz Sarlo fala sobre Modernidade Periférica [02 de outubro de 2010). Rio de Janeiro: O Globo. Entrevista a Guilherme Freitas. Disponível em $<$ http://blogs.oglobo.globo.com/prosa/post/critica-beatriz-sarlo-fala-sobre-modernidade-periferica-329148.html> Acessado em 08.mar.2018. 
SCHARLAU, B. (2001). Repensar la Colonia, las relaciones culturales y la traducción. lberoamericana III/12: p. $97-110$.

SCHARLAU, B. (2004). Traducir América latina: genealogia de un tópico de investigación. Estudios de Investigaciones Literarias y Culturales. Venezuela, nº 24, p. 15-33.

SOUZA, A. (2011). América latina, conceito e identidade: algumas reflexões da história. PRACS: Revista de Humanidades do Curso de Ciências Sociais. UNIFAP. Macapá. no 4 , p. 29-39. 